Original Research Paper

\title{
Effect of Essential Oils versus Home Remedies on Relieving Signs of Acute Respiratory Tract Infection among Children
}

\author{
${ }^{1}$ Abeer Abd El-Aziz Mohamed Madian, ${ }^{2}$ Mohammad Mahmoud Abd-Alhaseeb, \\ ${ }^{3}$ Ebtsam Salah Yonis Mahrous and ${ }^{3}$ Rodaina Ahmed Mokbel \\ ${ }^{1}$ Department of Community Health Nursing, Faculty of Nursing, Damanhour University, Egypt \\ ${ }^{2}$ Department of Pharmacology and Toxicology, Faculty of Pharmacy, Damanhour University, Egypt \\ ${ }^{3}$ Department of Pediatric Nursing, Faculty of Nursing, Damanhour University, Egypt
}

\author{
Article history \\ Received: 21-09-2020 \\ Revised: 12-02-2021 \\ Accepted: 12-02-2021 \\ Corresponding Author: \\ Mohammad Mahmoud Abd- \\ Alhaseeb \\ Department of Pharmacology \\ and Toxicology, Faculty of \\ Pharmacy, Damanhour \\ University, Egypt \\ Email: m.abdelhasseb@pharm.dmu.edu.eg
}

\begin{abstract}
Acute Respiratory Infection (ARI) accounts for more than 94 million cases annually and 1.9 million deaths among children worldwide. ARI is the most common cause of illness and mortality in children under five years old. The purpose of this study was to investigate the effect of essential oils versus home remedies on relieving signs and symptoms of ARI among children. This study was a non-randomized clinical trial done on 100 children who were assigned to two groups. The severity of symptoms, cough and sleep difficulty were compared in the two groups by using Structured Interview Schedule and the Canadian Acute Respiratory Illness and Flu Scale (CARIFS). The entire group that received essential oils (100\%) had mild level of cough and sleep difficulty after 7 days post-intervention, while $72 \%$ of the control (home remedies) group had a moderate level of these symptoms. Moreover, there was a marked decrease in all CARIFS items in the intervention group with decreased fever, vomiting, irritability, sore throat and headache post-intervention and there was a highly statistically significant difference among all CARIFS items between control and intervention groups at 7 days post-intervention. Mixture of five essential oils used in this study had more effect than home remedies on relieving signs and symptoms of ARI and this treatment is suggested as a safe and cost effective method to reduce ARI among children.
\end{abstract}

Keywords: Essential Oils, Home Remedies, Relieving, Acute Respiratory Tract Infection, Children

\section{Introduction}

Upper Respiratory Tract Infections (URTIs) occur commonly among children. They are typically of viral nature, which is characterized by being mild and selflimiting, but the symptoms can cause fever and make children irritable, sleepy and uncomfortable. The plan for recovery is to decrease symptoms and pain. While utilized excessively, Non-prescription cough and cold preparations may not be effective in controlling symptoms or reducing the disease (Carr and Nahata, 2006). They can cause a wide range of negative effects, including paradoxical reactions and unintentional overdose toxicity, especially in children less than three years of age (Chien et al., 2003).
Natural therapy including herbs is used either in addition to, or as a replacement for traditional Western medical or surgical treatment (Bardia et al., 2007; Breuner, 2002). Herbal preparations containing echinacea, propolis and vitamin $\mathrm{C}$ extracts have a significant beneficial effect on the incidence and severity of respiratory tract infections in young children (Cohen et al., 2004). Herbal essential oils are widely used in the treatment of respiratory tract infections, mostly because of their antibacterial and antiviral effects (Köteles et al., 2018). One of the most widely consumed singleingredient herbal teas is peppermint (Mentha piperita L.). It has major antimicrobial and antiviral activities; it also has a powerful antioxidant effect, anti-tumor actions and certain potential anti-allergenic effects (McKay and 
Blumberg, 2006). Honey has antibacterial efficacy against a diverse spectrum of URTI-causing bacteria (Francis et al., 2015).

\section{Significance of the Study}

Lower Respiratory Tract Infections (LRTIs) are a major cause of morbidity and mortality worldwide (Brini et al., 2017; Liu et al., 2016). They are among the most widespread causes of death in Africa. Generally, viruses are responsible for a large proportion of LRTIs. Bacteria are other causes of LRTIs such as Staphylococcus aureus which is the most common type of bacteria (Troeger et al., 2017; Ouedraogo et al., 2017). In Egypt, the dominant infectious pathogen identified in patients over 1 year of age was influenza (13.9\%). In infants from 1 to 11 months of age, the highest prevalence rates of hospitalized Acute Respiratory Infections (ARI) have been observed (1757.9-5537.5/100 000 population). The most commonly detected pathogen in this age group was the Respiratory Syncytial Virus (RSV) (Rowlinson et al., 2017). So, the present study aimed to investigate and evaluate the efficacy of using natural herbal oils from Mentha piperita, Rosmarinus officinalis, Eucalyptus globulusin, lemon extract and honey in relieving signs and symptoms of upper respiratory tract infection in children older than one year in comparison to home remedies only.

\section{Operational Definition of Acute Respiratory Tract Infection}

ARI was defined as an illness with fever and at least one respiratory symptom (nasal stuffiness, runny nose, cough or sore throat) and at least one systemic symptom (lethargy, myalgia and headache). The fever had to be measured at the enrolment visit as greater than $38.0^{\circ} \mathrm{C}$ orally or rectally, or greater than $37.5^{\circ} \mathrm{C}$ axillary, or reported by the parent to be of that magnitude earlier that day (Rowlinson et al., 2017).

\section{Aim of Study}

Consequently, the present study was executed to evaluate the effect of essential oils versus home remedies on relieving signs of acute respiratory tract infection among children.

\section{Hypotheses of the Study}

H1; Children who use essential oils display faster relieving signs of acute respiratory tract infection than those who use home remedies.

$\mathrm{H} 2$; Children who use home remedies display faster relieving signs of acute respiratory tract infection than those who use essential oils.

\section{Materials and Methods}

\section{Research Design}

A non-randomized controlled clinical trial research design was adopted to carry out this study.

\section{Setting}

The study was carried out at the following settings:

1- Out patients' clinics of children affiliated to the National Medical Institute of Damanhour City (Damanhour, Beheira, Egypt)

2- Children's homes

\section{Subjects}

Children suffering from respiratory tract infection and sore throat were conveniently selected from outpatients' clinics at the National Medical Institute of Damanhour City according to the following inclusion criteria:

- Age from 1- 6 years

- With no history of chronic diseases

- No cases of chronic adenotonsillar pathology, recurrent otitis, sinusitis, respiratory allergy, gastroesophageal reflux disease

- Willing to participate in the study

\section{Sample Size}

Based on the approximate monthly ratio of sick children with respiratory tract infection and sore throat who turned up to outpatients' clinics (50 cases/day), the sample size $(\mathrm{N}=100)$ was calculated taking $15 \%$ proportion of 5\% margin error and $95 \%$ confidence level

\section{Sampling Technique}

The study subjects were selected after checking the list of patients' rate in the setting daily and according to the previously mentioned inclusion criteria. The samples were equally alienated into the two study groups, where every odd number was assigned to the control group which comprised 50 children who were instructed to use home remedies regularly; and every even number was assigned to the intervention group which included 50 children who received inhalation device of essential oils.

Tools of Data Collection Two tools were utilized and filled by the researchers to collect data.

\section{Tool 1: "Structured Interview Schedule Sheet"}

It was developed by the researchers after a thorough review of relevant recent literature to collect data related to the mothers and their children and it was subdivided into 5 parts as follows: 


\section{Part 1: - Mothers' Related Data}

This part included the following personal characteristics: Age, educational level, occupation, residence, previous labor and type of delivery.

\section{Part 2: - Children's Related Data}

This part included data such as; age, gender, birth weight, current weight, height, type of feeding and if the child was exposed to negative smoking.

\section{Part 3: -Medical History of the Child Related to Acute Respiratory Tract Infection Data}

This part included data as; ARI episodes per year, illness duration, presence of fever, presence of tonsillitis, cough frequency, medications used in treatment, fluids taken during illness and presence of earache.

\section{Part 4: - Baseline Assessment Related Data}

It included 6 symptoms assessed by mothers as; fatigue, sore throat, cough, hoarseness or loss of voice, pain when talking and difficulty in breathing; in addition to 4 signs assessed by the physician at the outpatients' pediatric clinic as: Stridor, dyspnea, mucous secretions and fever. Each sign was graded as 0 (none) or 1 (positive sign). Thus, Patients were categorized as having a more severe disease if their initial clinical score was higher than 8 .

\section{Part 5: - Cough and Sleep Difficulty on the Previous Night among Children Related Data}

This part included four questions to assess cough and sleep during the previous night of illness among children reported by mothers as frequency and severity of cough and the ability to sleep for both the child and the mother as well. They were rated on a six-point Likert scale to indicate to what extent did the child suffer from cough in the previous night as follows: (0) Not at all, (1) occasional, (2) a little (3) somewhat, (4) a lot, (5) very much and (6) extremely. The total score was calculated and ranged from (0-24); it was categorized into three levels as follows:

\footnotetext{
- $\quad$ Mild (0-8)

- $\quad$ Moderate (9-16)

- $\quad$ Severe (17-24)
}

\section{Tool 2: The Canadian Acute Respiratory Illness and Flu Scale (CARIFS)}

The Canadian Acute Respiratory Illness and Flu Scale developed by (Jacobs et al., 2000) was used in clinical trials to assess children with ARI. The scale was composed of 18 items covering three domains; symptoms (e.g., cough, fever, runny nose, vomiting, need medication, sore throat and headache); function (e.g., moody, poor appetite, not interested in what's going on, irritability, not playing well, crying more than usual, not sleeping well, not responding to parents and not communicating well) and parental impact (e.g., clinginess of bed and need extra care). Construct validity was assessed by comparing the CARIFS score with physician, nurse and parental assessment of the child's health condition. The 18 items CARIFS is a valid measure of functional severity and burden of illness to the parent. Using the questionnaire before and after the intervention maximized the ability to assess disease severity and its impact on both the child and the parent. An ordinal coding system was used on a degree scale as follows: (no response or don't know $=-1$, no disease $=0$, minor disease $=1$, moderate disease $=2$ and major disease $=3$ ). The total code score was calculated by summation of item scores, this resulted in the final CARIFS of 18 items with a minimum score (no illness) of zero and a maximum score of 54; it was then categorized into the following four levels:

- No disease zero

- Minor disease 1-18

- Moderate disease 19-36

- Major disease 37-54

This tool was tested by (Jacobs et al., 2000) using correlation coefficient test of reliability $=0.905$.

\section{Methodology}

1. Permission: An official letter from the Faculty of Nursing was directed to the director of the National Medical Institute in Damanhour for earning his consent before collecting the data after explicating the study aim

2. Tool development: Tool (I) was developed by the researchers based on a review of relevant recent literature

3. Tool Validity: Tool (I) was examined for content validity by a jury of five experts in the field of community health nursing and pediatric nursing from Faculty of Nursing; Damanhour University and the suggested adjustments were done

4. Pilot study: A pilot study was performed on ten children ( $10 \%$ of the study sample) to ascertain the clarity, applicability and feasibility of the tools and to detect the obstacles that might hinder the data collection process (those ten children were excluded from the original sample). Consequently, all needed modifications were done

5. Data collection process: The overall data collection process took about nine months (from June 2019 to February 2020)

6. Baseline-assessment of children: Related data and past medical history regarding infection with 
acute respiratory tract for both the study and control groups were done by the researchers once using tool I and tool 2

7. Preparation of the herbal product: Essential oils of Mentha piperita, Rosmarinus officinalis, Eucalyptus globulusin and lemon extract was supplied from local supplier to Phrmacology department at Faculty of Pharmacy, Damanhour University. Then, one table spoonful of Honey added to one tablespoonful of Lemon extract, one table spoonful of Peppermint oil, one table spoonful of Rosemary oil and one table spoonful of Eucalyptus oil in an inhaled device designed and provided by local manufacturer to be used three times daily for two weeks

8. Thence, 100 children were randomly allocated and divided into two groups, intervention group who received essential oils and control group who received home remedies only

Data collection process was carried out through four phases:
a. Interviewing
b. Assessment
c. Implementation
d. Evaluation

\section{Interviewing phase}

Initial interview, the researchers met all mothers and children at the out-patients' clinic. Then the children, who fulfilled the pre-determined inclusion criteria, were recruited and apportioned into the two study groups and their mothers were interviewed individually.

\section{Assessment Phase}

In this phase, children were examined firstly by the researchers to collect the baseline data related to respiratory tract infections before the intervention of both groups.

\section{Implementation Phase}

\section{Technique of Procedure}

The two groups constituted 100 children; each child was assigned into one of the 2 groups.

\section{Group 1}

Intervention group received essential oils in an inhalation device to be used three times daily for two weeks. The first time of using the inhalation device was after baseline assessment and outside the physician's room, following this evaluation, mothers were advised to apply the spray to their children at home for 14 consecutive days in a dosage of 4 sprayings each time, 3 times a day. Children were visited by the researchers daily for 7 days to evaluate their signs and symptoms of ARI by CARIFS. Children in intervention group were assessed twice by their physician (first and 7th day), seven times by the researches and 14 times by their mothers. The researchers telephoned each child's home at least 2 times daily from day 8 till day 14 to inquire about the follow up, answer any questions that may have arisen about completing the trial and fostering their compliance with trial keeping. The timing of the calls was scheduled with parents. (The telephone based assessment from the 8th day till the 14th day was not recorded).

\section{Group 2}

Control group who received regular warm home remedies 6 times/day.

\section{Evaluation Phase}

Outcome was measured in terms of relieving the children signs and symptoms of respiratory tract infection and sore throats.

\section{Ethical Considerations}

- Permission to conduct the study was obtained from the ethical committee in the Faculty of Nursing, Damanhour University with ethical code N3212019

- All eligible mothers were informed about the aim of the study, the methodology of this trial and their questions were answered, then written consent was obtained from each mother before the beginning of the study

- Mothers and children privacy and confidentiality was maintained

\section{Statistical Analysis}

After collecting data, responses were entered to the Statistical Package for Social Sciences (SPSS) software version 20.0. The level of significance ( $p$ value) was set at 0.05 .

The following statistical tests were used:

- Continuous variables were represented as means \pm SD

- Categorical variables were represented as frequencies and percentages

- Chi-square test: For comparing categorical variables.

- Fisher Exact correction: For chi-square correction when more than $20 \%$ of the cells have expected count less than 5

- Student t-test: A parametric statistical test for comparing the mean for two independent groups

- Paired t-test: A parametric statistical test for comparing the mean for the same group pre and post intervention 
- Pearson coefficient: For measuring the strength of the association between variables

- Graphical presentation: Was done for data visualization by using Microsoft Excel

\section{Results}

\section{Characteristics of Mothers in Control and Intervention}

Table 1 exhibited that, the majority of mothers $(88 \%)$ in control group and less than two thirds $(62 \%)$ of them in intervention group their age ranged between $30-40$ years with mean $32.1 \pm 5.03$ and 31.6 \pm 5.7 years, respectively. In relation to the educational level of the mothers, it was found that the highest percent 32 and $48 \%$ of control and intervention groups had technical school education, respectively. The majority of mothers in both groups were house wives lived in rural area. As well, $64 \%$ of the mothers in control group had history of previous labor, $53.1 \%$ of them had a caesarean section delivery. While, $70 \%$ of the mothers in the intervention group had history of previous labor, $62.9 \%$ of them had a caesarean section delivery too. No statistical significant differences were found between the mothers in the control and intervention groups in relation to their characteristics.

\section{Characteristics of Children in Control and Intervention}

Table 2 clarified that, the highest percent of the children (70 and $64 \%$ of the control and intervention groups, respectively) their age ranged between $>3-6$ years with mean $4.22 \pm 1.38$ and $3.84 \pm 1.60$ years. Likewise, more than half (60 and 56\%) of the control and intervention groups in that order were girls. Regarding birth weight, in both groups similarly, the majority (94\%) of them their birth weight ranged between $3-4 \mathrm{~kg}$ with mean $3.23 \pm 0.47$ and $3.22 \pm 0.32 \mathrm{~kg}$ in the control and intervention groups, respectively. Related to body weight, about two-thirds (64\%) of the control group their body weight ranged between $>15-25$ $\mathrm{kg}$ with mean $17.28 \pm 3.45 \mathrm{~kg}$. While, $(56 \%)$ of the intervention group their body weight also ranged between $>15-25 \mathrm{~kg}$ with mean $16.18 \pm 3.52 \mathrm{~kg}$. Regarding height, the majority (76 and 66\%) of the control and intervention groups in that order, their height ranged between >95-115 with mean 101.98 \pm 8.03 and $99.74 \pm 9.92 \mathrm{~cm}$. As regard to feeding, the majority (90 and $82 \%$ ) of the control and intervention groups were breast fed, respectively. Meanwhile, 56 and $62 \%$ of the control and intervention groups in that order suffered from negative smoking. No statistical significant differences were found between the children in both groups in relation to their characteristics.

Table 1: Distribution of mothers in control and intervention groups in line with their characteristics

\begin{tabular}{|c|c|c|c|c|c|}
\hline \multirow[b]{2}{*}{ Characteristics } & \multicolumn{2}{|c|}{$*$ Control group $(\mathrm{n}=50)$} & \multicolumn{2}{|c|}{$* *$ Intervention group $(\mathrm{n}=50)$} & \multirow[b]{2}{*}{ Test of Significance } \\
\hline & $\mathrm{N}$ & $\%$ & $\mathrm{~N}$ & $\%$ & \\
\hline \multicolumn{6}{|l|}{ Age } \\
\hline $19-<30$ & 6 & 12 & 19 & 38 & $\mathrm{t}=0.463$ \\
\hline $30-40$ & 44 & 88 & 31 & 62 & $\mathrm{p}=0.644$ \\
\hline $\bar{x} \pm$ S.D & \multicolumn{2}{|l|}{$32.1 \pm 5.03$} & \multicolumn{2}{|l|}{$31.6 \pm 5.7$} & \\
\hline \multicolumn{6}{|l|}{ Educational level } \\
\hline Illiterate & 10 & 20 & 7 & 14 & \multirow{5}{*}{$\begin{array}{l}\mathrm{FET}=4.439 \\
\mathrm{p}=0.361\end{array}$} \\
\hline Read and write & 2 & 4 & 2 & 4 & \\
\hline Preparatory school & 8 & 16 & 3 & 6 & \\
\hline Technical school & 16 & 32 & 24 & 48 & \\
\hline University & 14 & 28 & 14 & 28 & \\
\hline \multicolumn{6}{|l|}{ Occupation } \\
\hline House wife & 42 & 84 & 44 & 88 & $X^{2}=0.332$ \\
\hline Employee & 8 & 16 & 6 & 12 & $\mathrm{p}=0.564$ \\
\hline \multicolumn{6}{|l|}{ Residence } \\
\hline Rural & 43 & 86 & 41 & 82 & $X^{2}=0.298$ \\
\hline Urban & 7 & 14 & 9 & 18 & $\mathrm{p}=0.585$ \\
\hline \multicolumn{6}{|l|}{ Previous labor } \\
\hline Yes & 32 & 64 & 35 & 70 & $X^{2}=0.407$ \\
\hline No & 18 & 36 & 15 & 30 & $\mathrm{p}=0.523$ \\
\hline Type of delivery & $(\mathrm{N}=32)$ & & $(\mathrm{N}=35)$ & & \\
\hline Normal & 15 & 46.9 & 13 & 37.1 & $X^{2}=0.651$ \\
\hline Caesarean section & 17 & 53.1 & 22 & 62.9 & $\mathrm{p}=0.420$ \\
\hline
\end{tabular}

*control group; received home remedies; **intervention group; received essential oils; FET: Fisher Exact Test; $\mathrm{x}^{2}$ : Chi square test; t: student t-test; Level of significance at $\mathrm{p} \leq 0.05$ 
Table 2: Distribution of children in control and intervention groups in line with their characteristics

\begin{tabular}{|c|c|c|c|c|c|}
\hline \multirow[b]{2}{*}{ Characteristics } & \multicolumn{2}{|c|}{$*$ Control group $(\mathrm{n}=50)$} & \multicolumn{3}{|c|}{$* *$ Intervention group $(\mathrm{n}=50)$} \\
\hline & $\mathrm{N}$ & $\%$ & $\mathrm{~N}$ & $\%$ & Test of significance \\
\hline \multicolumn{6}{|l|}{ Age } \\
\hline $1-3$ & 15 & 30 & 18 & 36 & $t=1.264$ \\
\hline$>3-6$ & 35 & 70 & 32 & 64 & $p=0.209$ \\
\hline $\bar{x} \pm$ S.D & \multicolumn{2}{|c|}{$4.22 \pm 1.38$} & \multicolumn{3}{|c|}{$3.84 \pm 1.60$} \\
\hline \multicolumn{6}{|l|}{ Gender } \\
\hline Boys & 20 & 40 & 22 & 44 & $X^{2}=2.564$ \\
\hline Girls & 30 & 60 & 28 & 56 & $\mathrm{p}=0.109$ \\
\hline \multicolumn{6}{|l|}{ Birth weight $/ \mathrm{kg}$} \\
\hline$<3$ & 3 & 6 & 3 & 6 & $\mathrm{t}=0.123$ \\
\hline 3- 4 & 47 & 94 & 47 & 94 & $\mathrm{p}=0.902$ \\
\hline $\bar{x} \pm$ S.D & \multicolumn{2}{|c|}{$3.23 \pm 0.47$} & \multicolumn{3}{|c|}{$3.22 \pm 0.32$} \\
\hline \multicolumn{6}{|c|}{ Current body weight $/ \mathrm{kg}$} \\
\hline $9-15$ & 18 & 36 & 22 & 44 & $\mathrm{t}=1.576$ \\
\hline$>15-25$ & 32 & 64 & 28 & 56 & $\mathrm{p}=0.118$ \\
\hline $\bar{x} \pm$ S.D & \multicolumn{2}{|c|}{$17.28 \pm 3.45$} & \multicolumn{3}{|c|}{$16.18 \pm 3.52$} \\
\hline \multicolumn{6}{|l|}{ Height/cm } \\
\hline $80-95$ & 12 & 24 & 17 & 34 & $\mathrm{t}=1.241$ \\
\hline$>95-115$ & 38 & 76 & 33 & 66 & $\mathrm{p}=0.218$ \\
\hline $\bar{x} \pm$ S.D & \multicolumn{2}{|c|}{$101.98 \pm 8.03$} & \multicolumn{3}{|c|}{$99.74 \pm 9.92$} \\
\hline \multicolumn{6}{|l|}{ Feeding } \\
\hline Breast feeding & 45 & 90 & 41 & 82 & $\mathrm{X}^{2}=1.329$ \\
\hline Artificial feeding & 5 & 10 & 9 & 18 & $P=0.249$ \\
\hline \multicolumn{6}{|l|}{ Negative smoking } \\
\hline Yes & 28 & 56 & 31 & 62 & $X^{2}=0.372$ \\
\hline No & 22 & 44 & 19 & 38 & $P=0.542$ \\
\hline
\end{tabular}

*control group; received home remedies; **intervention group; received essential oils; $\mathrm{x}^{2}$ : Chi square test; $\mathrm{t}$ : student $\mathrm{t}$ - test; Level of significance at $\mathrm{p} \leq 0.05$

\section{Medical History of Acute Respiratory Infection in Control and Intervention}

Table 3 publicized that, the highest percent 60 and $64 \%$ of children in control and intervention groups suffered from ARI episodes 2-3 times/year, respectively. Also, the highest percent 60 and $66 \%$ of children in the control and intervention groups their illness duration was more than two days, respectively. Also, majority 96 and $92 \%$ of the control and intervention groups in that order had fever along with their disease. Moreover, 66 and $74 \%$ of the control and intervention groups had tonsillitis, respectively. Meanwhile, 54\% of the control group and $46 \%$ of the intervention group their cough frequency was $6-<10$ times with mean $8.08 \pm 2.79$ and $7.16 \pm 3.07$ among control and intervention groups, respectively. Correspondingly, the majority of them 82 and $76 \%$ were given antipyretic to treat fever in control and intervention groups, respectively. Moreover, $42 \%$ of the control group were using peppermint during disease. While, $40 \%$ of the intervention group were using Anise during disease. Also, 56\% of the control group always suffered from earache. While, $60 \%$ of the intervention group didn't suffer from earache. No statistical significant differences were found among the children in control and intervention groups in relation to their medical history of acute respiratory infection.

\section{Basic Assessment of Control and Intervention}

Table 4 demonstrated that, there was a marked decrease in most of the symptoms assessed by mothers of the control group such as fatigue, sore throat and difficulty in breathing post intervention with highly statistically significant difference at $(\mathrm{P}<0.01)$ between pre and post intervention. Moreover, there was a marked decrease in total symptoms assessed by mothers of the intervention group as fatigue, cough and hoarseness of voice post intervention with highly statistically significant difference at $(\mathrm{P}<0.01)$ between pre and post intervention. As well there was a statistically significant difference in most of the symptoms assessed by mothers between control and intervention groups as fatigue, sore throat and cough post intervention with highly statistically significant difference at $(\mathrm{P}<0.01)$.

Furthermore, there was a marked decrease in sings assessed by physician of control group as stridor, dyspnea and systemic fever $>38^{\circ} \mathrm{C}$ post intervention with highly statistically significant difference at $(\mathrm{P}<0.01)$ between pre and post intervention. Also, there was a marked decrease in total sings assessed by physician of intervention group as stridor, mucous secretion and systemic fever $>38^{\circ} \mathrm{C}$ post intervention with highly statistically significant difference at $(\mathrm{P}<0.01)$ between pre and post intervention. Also, there was a statistically 
significant difference between control and intervention groups regarding stridor and mucous secretion assessed by physician post intervention with highly statistically significant difference at $(\mathrm{P}<0.01)$.

Table 3: Distribution of children in control and intervention groups in line with their medical history of Acute Respiratory Infection (ARI)

\begin{tabular}{|c|c|c|c|c|c|}
\hline \multirow[b]{2}{*}{ Characteristics } & \multicolumn{2}{|c|}{$*$ Control group $(\mathrm{n}=50)$} & \multicolumn{2}{|c|}{$* *$ Intervention group $(\mathrm{n}=50)$} & \multirow[b]{2}{*}{ Test of significance } \\
\hline & $\mathrm{N}$ & $\%$ & $\mathrm{~N}$ & $\%$ & \\
\hline \multicolumn{6}{|l|}{ ARI episodes/year } \\
\hline Once/year & 6 & 12 & 8 & 16 & $X^{2}=1.017$ \\
\hline 2-3 year & 30 & 60 & 32 & 64 & $\mathrm{p}=0.601$ \\
\hline 4-5/year & 14 & 28 & 10 & 20 & \\
\hline \multicolumn{6}{|l|}{ Illness duration } \\
\hline One day & 2 & 4 & 3 & 6 & $\mathrm{FET}=0.910$ \\
\hline Two days & 18 & 36 & 14 & 28 & $\mathrm{p}=0.689$ \\
\hline More than two days & 30 & 60 & 33 & 66 & \\
\hline \multicolumn{6}{|l|}{ Fever associated with illness } \\
\hline Yes & 48 & 96 & 46 & 92 & $\mathrm{FET}=0.177$ \\
\hline No & 2 & 4 & 4 & 8 & $\mathrm{p}=0.674$ \\
\hline \multicolumn{6}{|l|}{ Presence of tonsillitis } \\
\hline Yes & 33 & 66 & 37 & 74 & $X^{2}=0.762$ \\
\hline No & 17 & 34 & 13 & 26 & $\mathrm{p}=0.383$ \\
\hline \multicolumn{6}{|l|}{ Cough frequency } \\
\hline $2-<6$ & 6 & 12 & 18 & 36 & $\mathrm{t}=1.567$ \\
\hline $6-<10$ & 27 & 54 & 23 & 46 & $\mathrm{p}=0.120$ \\
\hline $10-14$ & 17 & 34 & 9 & 18 & \\
\hline $\bar{x} \pm$ S.D & $8.08 \pm 2.79$ & & & & \\
\hline \multicolumn{6}{|l|}{ \# Prescribed medication used } \\
\hline Antipyretic & 41 & 82 & 38 & 76 & $X^{2}=0.542 p=0.461$ \\
\hline Antibiotic & 22 & 44 & 19 & 38 & $\mathrm{X}^{2}=0.372 \mathrm{p}=0.542$ \\
\hline Decongestant & 19 & 38 & 17 & 34 & $X^{2}=0.174 p=0.677$ \\
\hline Cough suppressants & 15 & 30 & 13 & 26 & $\mathrm{X}^{2}=0.198 \mathrm{p}=0.656$ \\
\hline \multicolumn{6}{|c|}{ Most frequent fluid used during illness } \\
\hline Anise & 12 & 24 & 20 & 40 & $\mathrm{FET}=6.452$ \\
\hline Peppermint & 21 & 42 & 19 & 38 & $p=0.163$ \\
\hline Warm lemon & 10 & 20 & 3 & 6 & \\
\hline Hot water mixed with honey & 3 & 6 & 2 & 4 & \\
\hline Others helba or caraway & 4 & 8 & 6 & 12 & \\
\hline \multicolumn{6}{|c|}{ Earache associated with illness } \\
\hline Yes & 28 & 56 & 20 & 40 & $X^{2}=2.564$ \\
\hline No & 22 & 44 & 30 & 60 & $\mathrm{p}=0.109$ \\
\hline
\end{tabular}

*Control group; received home remedies; **intervention group; received essential oils; \# More than one answer; t: student t- test; FET: Fisher Exact test; $\mathrm{x}^{2}$ : Chi square test; Level of significance at $\mathrm{p} \leq 0.05$

Table 4: Mean scores of control and intervention groups in line with their basic assessment

\begin{tabular}{|c|c|c|c|c|c|c|c|c|c|c|c|c|}
\hline & \multicolumn{2}{|c|}{ *Control group } & \multirow[b]{2}{*}{ to. test } & \multirow[b]{2}{*}{$\begin{array}{l}\text { p. } \\
\text { value }\end{array}$} & \multicolumn{2}{|c|}{ **Intervention group } & \multirow[b]{2}{*}{ to. test } & \multirow[b]{2}{*}{ p. value } & \multirow[b]{2}{*}{$\begin{array}{l}\text { Post control } \\
\text { Group } \bar{x} \\
\pm \text { S. D }\end{array}$} & \multirow{2}{*}{$\begin{array}{l}\text { Post } \\
\text { intervention } \\
\text { group } \bar{x} \\
\pm \text { S. D }\end{array}$} & \multirow[b]{2}{*}{ t. test } & \multirow[b]{2}{*}{ p. value } \\
\hline & $\begin{array}{l}\text { Pre } \bar{x} \\
\pm \text { S.D }\end{array}$ & $\begin{array}{l}\text { Post } \bar{x} \\
\pm \text { S. D }\end{array}$ & & & $\begin{array}{l}\text { Pre } \bar{x} \\
\pm \text { S.D }\end{array}$ & $\begin{array}{l}\text { Post } \bar{x} \\
\pm \text { S. D }\end{array}$ & & & & & & \\
\hline Fatigue & $1.0 \pm 0.0$ & $0.50 \pm 0.50$ & 7.000 & 0.000 & $1.0 \pm 0.0$ & $0.02 \pm 0.14$ & 49.000 & 0.000 & $0.50 \pm 0.50$ & $0.02 \pm 0.14$ & 6.471 & 0.000 \\
\hline Sore throat & $1.0 \pm 0.0$ & $0.78 \pm 0.41$ & 3.718 & 0.001 & $1.0 \pm 0.0^{\mathrm{a}}$ & $0.0 \pm 0.0^{\mathrm{a}}$ & & & $0.78 \pm 0.41$ & $0.0 \pm 0.0$ & 13.181 & 0.000 \\
\hline Cough & $1.0 \pm 0.0$ & $0.96 \pm 0.19$ & 1.429 & 0.159 & $1.0 \pm 0.0$ & $0.30 \pm 0.46$ & 10.693 & 0.000 & $0.96 \pm 0.19$ & $0.30 \pm 0.46$ & 9.270 & 0.000 \\
\hline Hoarseness or loss of voice & $1.0 \pm 0.0^{\mathrm{a}}$ & $0.0 \pm 0.0^{\mathrm{a}}$ & & & $0.98 \pm 0.14$ & $0.0 \pm 0.0$ & 49.000 & 0.000 & $0.0 \pm 0.0^{\mathrm{b}}$ & $0.0 \pm 0.0^{\mathrm{b}}$ & & \\
\hline Difficulty in breathing & $1.0 \pm 0.0$ & $0.08 \pm 0.27$ & 23.738 & 0.000 & $1.0 \pm 0.0^{\mathrm{a}}$ & $0.0 \pm 0.0^{\mathrm{a}}$ & & & $0.08 \pm 0.27$ & $0.0 \pm 0.0$ & 2.064 & 0.044 \\
\hline Total & $6.0 \pm 0.0$ & $2.36 \pm 0.96$ & 26.704 & 0.000 & $5.98 \pm 0.14$ & $0.32 \pm 0.47$ & 77.052 & 0.000 & $2.36 \pm 0.96$ & $0.32 \pm 0.47$ & 13.445 & 0.000 \\
\hline \multicolumn{13}{|c|}{ Signs assessed by the physician: } \\
\hline Stridor & $1.0 \pm 0.0$ & $0.64 \pm 0.48$ & 5.250 & 0.000 & $1.0 \pm 0.0$ & $0.02 \pm 0.14$ & 49.000 & 0.000 & $0.64 \pm 0.48$ & $0.02 \pm 0.14$ & 8.680 & 0.000 \\
\hline Dyspnea & $1.0 \pm 0.0$ & $0.04 \pm 0.19$ & 34.293 & 0.000 & $1.0 \pm 0.0^{\mathrm{a}}$ & $0.0 \pm 0.0^{\mathrm{a}}$ & & & $0.04 \pm 0.19$ & $0.0 \pm 0.0$ & 1.429 & 0.159 \\
\hline Mucous secretion & $1.0 \pm 0.0$ & $0.92 \pm 0.27$ & 2.064 & 0.044 & $1.0 \pm 0.0$ & $0.30 \pm 0.46$ & 10.693 & 0.000 & $0.92 \pm 0.27$ & $0.30 \pm 0.46$ & 8.150 & 0.000 \\
\hline Systemic fever $>38^{\circ} \mathrm{C}$ & $1.0 \pm 0.0$ & $0.08 \pm 0.27$ & 23.738 & 0.000 & $0.98 \pm 0.14$ & $0.02 \pm 0.14$ & 34.293 & 0.000 & $0.08 \pm 0.27$ & $0.02 \pm 0.14$ & 1.376 & 0.173 \\
\hline Total & $4.0 \pm 0.0$ & $1.68 \pm 0.76$ & 21.368 & 0.000 & $3.98 \pm 0.14$ & $0.34 \pm 0.47$ & 53.083 & 0.000 & $1.68 \pm 0.76$ & $0.34 \pm 0.47$ & 10.474 & 0.000 \\
\hline
\end{tabular}


Abeer Abd El-Aziz Mohamed Madian et al. / American Journal of Infectious Diseases 2021, 17 (1): 7.21 DOI: 10.3844/ajidsp.2021.7.21

\begin{tabular}{|c|c|c|c|c|c|c|c|c|c|c|c|c|}
\hline & \multicolumn{2}{|c|}{$*$ Control group } & \multirow[b]{2}{*}{$t_{0}$. test } & \multirow[b]{2}{*}{ P. value } & \multicolumn{2}{|c|}{$* *$ Intervention group } & \multirow[b]{2}{*}{$t_{0}$. test } & \multirow[b]{2}{*}{ P. value } & \multirow{2}{*}{$\begin{array}{l}\text { Post control } \\
\text { group } \\
\bar{x} \pm \mathrm{S} \text {. D }\end{array}$} & \multirow{2}{*}{$\begin{array}{l}\text { Post } \\
\text { intervention } \\
\text { group } \\
\bar{x} \pm \text { S. D }\end{array}$} & \multirow[b]{2}{*}{ t. test } & \multirow[b]{2}{*}{ P. value } \\
\hline & $\begin{array}{l}\text { Pre } \bar{x} \\
\pm \text { S.D }\end{array}$ & $\begin{array}{l}\text { Post } \bar{x} \\
\pm \text { S.D }\end{array}$ & & & $\begin{array}{l}\text { Pre } \bar{x} \\
\pm \text { S.D }\end{array}$ & $\begin{array}{l}\text { Post } \bar{x} \\
\pm \text { S.D }\end{array}$ & & & & & & \\
\hline $\begin{array}{l}\text { Frequency of the child's } \\
\text { cough last night }\end{array}$ & $5.60 \pm 0.57$ & $2.86 \pm 0.85$ & 20.080 & 0.000 & $5.32 \pm 0.58$ & $0.72 \pm 0.53$ & 44.653 & 0.000 & $2.86 \pm 0.85$ & $0.72 \pm 0.53$ & 14.965 & 0.000 \\
\hline $\begin{array}{l}\text { Effect of last night's cough } \\
\text { on child's ability to sleep }\end{array}$ & $5.56 \pm 0.57$ & $2.84 \pm 0.84$ & 20.755 & 0.000 & $5.34 \pm 0.59$ & $0.42 \pm 0.57$ & 41.963 & 0.000 & $2.84 \pm 0.84$ & $0.42 \pm 0.57$ & 16.790 & 0.000 \\
\hline $\begin{array}{l}\text { Severity of child's cough } \\
\text { last night }\end{array}$ & $5.52 \pm 0.57$ & $2.82 \pm 0.82$ & 19.598 & 0.000 & $5.30 \pm 0.58$ & $0.44 \pm 0.57$ & 42.512 & 0.000 & $2.82 \pm 0.82$ & $0.44 \pm 0.57$ & 16.710 & 0.000 \\
\hline Total & $22.2 \pm 2.22$ & $11.16 \pm 3.15$ & 21.535 & 0.000 & $21.26 \pm 2.23$ & $1.76 \pm 1.86$ & 51.555 & 0.000 & $11.16 \pm 3.15$ & $1.76 \pm 1.86$ & 18.113 & 0.000 \\
\hline
\end{tabular}

*control group; received home remedies; **intervention group; received essential oils; to: Paired t- test; $\mathrm{t}$ : Student $\mathrm{t}$ - test; Level of significance at $\mathrm{p} \leq 0.05$

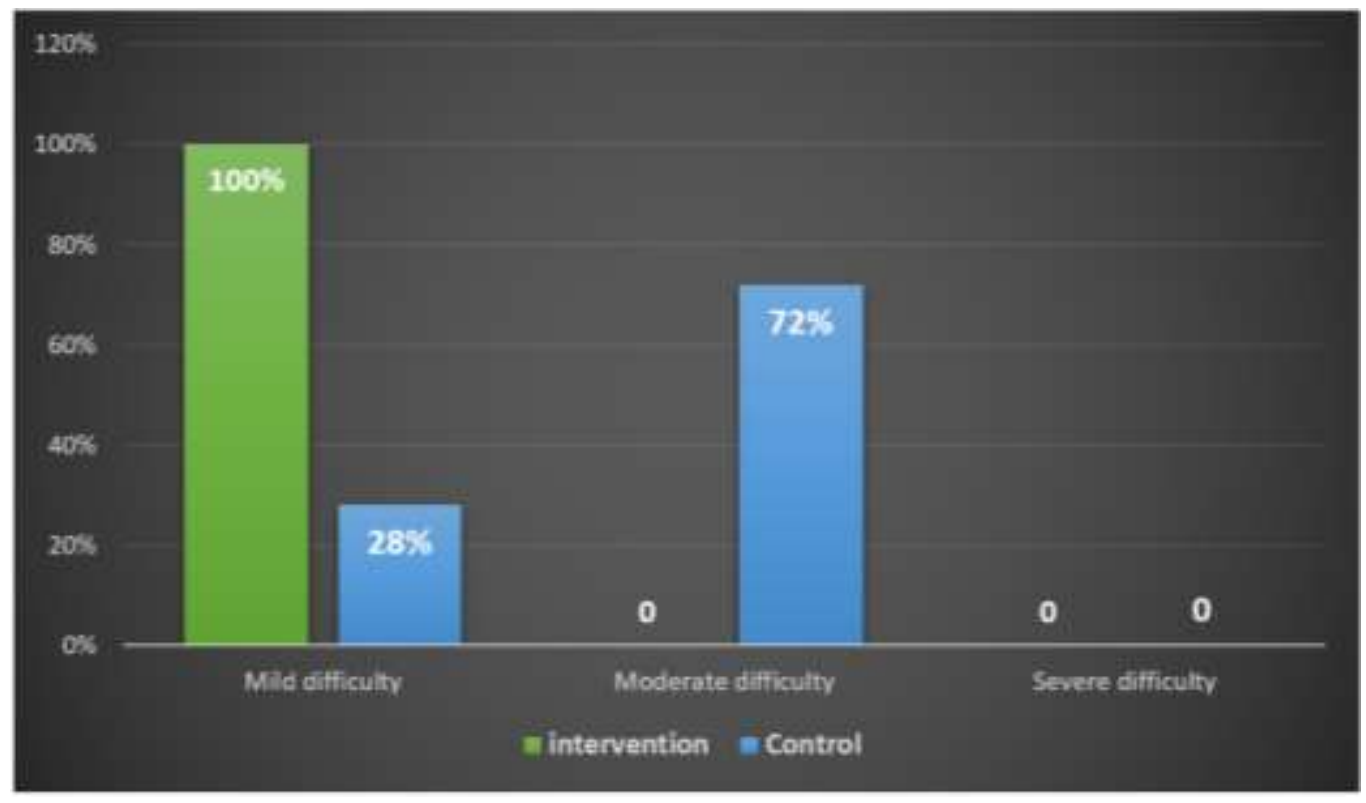

Fig. 1: Cough and sleep difficulty at night after 7 days post intervention among control and intervention groups

Mean Scores of Control and Intervention Groups on the Previous Night before Disease and after 7 Days Post Intervention

Table 5 verified that, there was a marked decrease in total cough and sleep difficulty on the previous night before disease among the control group as decreased child's cough frequency after 7 days post intervention with highly statistically significant difference at $(\mathrm{P}<0.01)$ between pre and post intervention. Moreover, there was a marked decrease in total cough and sleep difficulty on the previous night before disease among intervention group as reduced effect of children's cough on their ability to sleep post intervention with highly statistically significant difference at $(\mathrm{P}<0.01)$ between pre and post intervention. Besides, there was a high statistically significant difference in total cough and sleep difficulty on the previous night before disease between control and intervention groups post intervention at $(\mathrm{P}<0.01)$.

\section{Cough and Sleep Difficulty among Control and Intervention}

Figure 1 depicted that, the entire intervention group had mild level of total cough and sleep difficulty after 7 days post intervention. While, less than three quarters $(72 \%)$ of the control group had moderate level of total cough and sleep difficulty after 7 days post intervention. Also, 28\% of the control group had mild level of total cough and sleep difficulty after 7 days post intervention.

\section{Canadian Acute Respiratory Illness and Flu Scale at the First Contact and after 7 Days of Intervention}

Table 6 proved that, there was a marked decrease in all items of the Canadian acute respiratory illness and flu scale of the control group post intervention with highly statistically significant difference at $(\mathrm{P}<0.01)$ between pre and post intervention. Also, there was a marked decrease in all items of the Canadian acute respiratory illness and flu scale of the intervention group post 
intervention with highly statistically significant difference at $(\mathrm{P}<0.01)$ between pre and post intervention.

\section{Post Interventions Mean Scores of Children in Control and Intervention}

Table 7 portrayed that, there was a highly statistically significant difference in total Canadian acute respiratory illness and flu scale between control and intervention groups after 7 days post intervention at $(\mathrm{P}<0.01)$.

\section{Studied children after 7 Days of Intervention among Both Groups in line with Total Canadian Acute Respiratory Illness and Flu Scale}

Figure 2 bared that, 52 and $6 \%$ of the intervention and control groups didn't have signs and symptoms of respiratory disease after 7 days post intervention, respectively. Also, 48 and $76 \%$ of the intervention and control groups had minor level of respiratory disease after 7 days post intervention, respectively. While, $18 \%$ of the control group had moderate level of respiratory disease post intervention.

\section{Correlation Matrix between Variables Post Intervention in the Intervention Group}

Table 8 declared that, there was a highly significant positive correlation between total Cough and Sleep of the intervention group and their Canadian acute respiratory illness and flu scale and their Based assessment post intervention at $(\mathrm{P}<0.01)$.

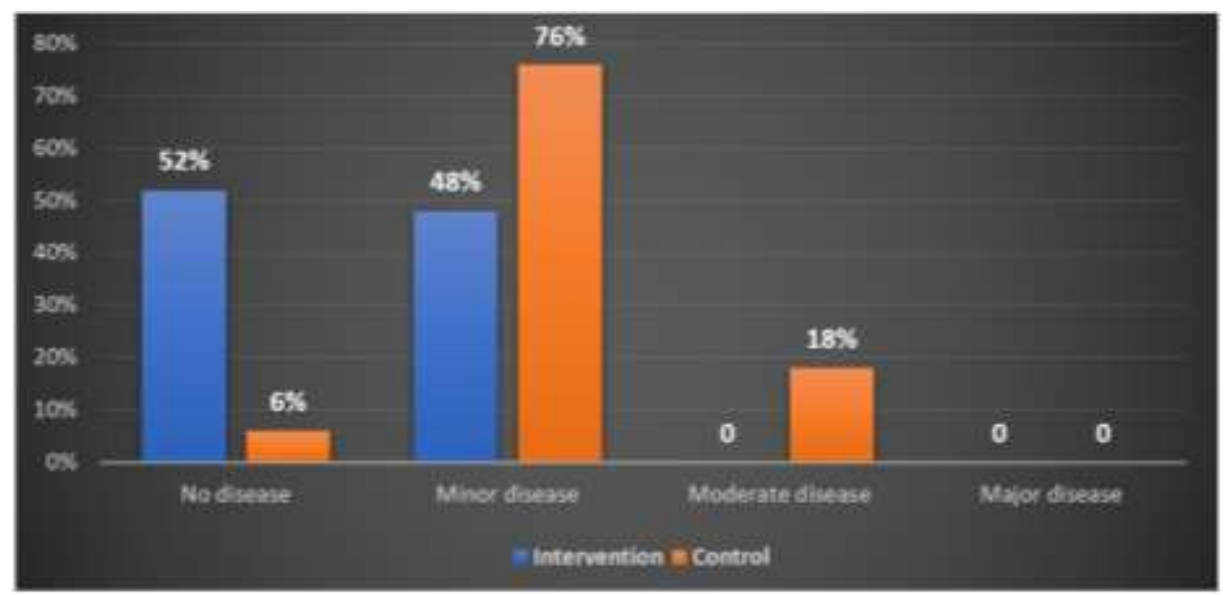

Fig. 2: Distribution of studied children after 7 days of intervention among both groups in line with total Canadian acute respiratory illness and flu scale

Table 6: Mean scores of control and intervention groups in line with Canadian Acute Respiratory Illness and Flu Scale at the first contact and after 7 days of intervention

\begin{tabular}{|c|c|c|c|c|c|c|c|c|}
\hline & \multicolumn{2}{|c|}{ *Control group } & \multirow[b]{2}{*}{$\mathrm{t}_{0}$. test } & \multirow[b]{2}{*}{ P. value } & \multicolumn{4}{|c|}{$* *$ Intervention group } \\
\hline & Pre $\bar{x} \pm$ S.D & Post $\bar{x} \pm$ S.D & & & Pre $\bar{x} \pm$ S.D & Post $\bar{x} \pm$ S.D & $\mathrm{t}_{0}$. test & P. value \\
\hline Fever & $2.84 \pm 0.37$ & $0.18 \pm 0.38$ & 39.307 & 0.000 & $2.86 \pm 0.53$ & $0.0 \pm 0.0$ & 37.807 & 0.000 \\
\hline Cough & $2.96 \pm 0.19$ & $1.18 \pm 0.48$ & 30.079 & 0.000 & $3.00 \pm 0.00$ & $0.44 \pm 0.50$ & 36.101 & 0.000 \\
\hline Runny nose & $2.96 \pm 0.19$ & $1.20 \pm 0.49$ & 28.847 & 0.000 & $2.94 \pm 0.31$ & $0.30 \pm 0.46$ & 35.538 & 0.000 \\
\hline Vomiting & $2.76 \pm 0.43$ & $0.14 \pm 0.40$ & 34.935 & 0.000 & $2.66 \pm 0.68$ & $0.0 \pm 0.0$ & 27.323 & 0.000 \\
\hline Moody & $2.88 \pm 0.32$ & $0.66 \pm 0.47$ & 26.986 & 0.000 & $2.98 \pm 0.14$ & $0.0 \pm 0.0$ & 149.00 & 0.000 \\
\hline Poor appetite & $2.96 \pm 0.19$ & $0.62 \pm 0.49$ & 34.578 & 0.000 & $2.96 \pm 0.19$ & $0.02 \pm 0.14$ & 86.657 & 0.000 \\
\hline Irritable & $2.96 \pm 0.19$ & $0.58 \pm 0.49$ & 34.323 & 0.000 & $2.96 \pm 0.19$ & $0.0 \pm 0.0$ & 105.736 & 0.000 \\
\hline Not playing well & $2.96 \pm 0.19$ & $0.58 \pm 0.49$ & 34.323 & 0.000 & $2.96 \pm 0.19$ & $0.0 \pm 0.0$ & 105.736 & 0.000 \\
\hline Need extra care & $2.96 \pm 0.19$ & $0.68 \pm 0.47$ & 35.546 & 0.000 & $2.96 \pm 0.19$ & $0.0 \pm 0.0$ & 105.736 & 0.000 \\
\hline Crying more than usual & $2.92 \pm 0.27$ & $0.60 \pm 0.49$ & 29.769 & 0.000 & $2.88 \pm 0.32$ & $0.0 \pm 0.0$ & 62.038 & 0.000 \\
\hline Clinginess of bed & $2.96 \pm 0.19$ & $0.72 \pm 0.45$ & 36.714 & 0.000 & $2.88 \pm 0.32$ & $0.0 \pm 0.0$ & 62.038 & 0.000 \\
\hline Not sleeping well & $2.96 \pm 0.19$ & $0.80 \pm 0.40$ & 41.243 & 0.000 & $2.96 \pm 0.19$ & $0.0 \pm 0.0$ & 105.736 & 0.000 \\
\hline Need medication & $2.96 \pm 0.19$ & $0.86 \pm 0.49$ & 32.078 & 0.000 & $2.96 \pm 0.19$ & $0.0 \pm 0.0$ & 105.736 & 0.000 \\
\hline Headache & $2.60 \pm 0.98$ & $0.56 \pm 0.57$ & 17.337 & 0.000 & $2.38 \pm 1.39$ & $0.0 \pm 0.0$ & 12.037 & 0.000 \\
\hline Not responding to parents & $2.96 \pm 0.19$ & $0.62 \pm 0.49$ & 34.578 & 0.000 & $2.94 \pm 0.23$ & $0.0 \pm 0.0$ & 86.657 & 0.000 \\
\hline Can't communicate well & $2.96 \pm 0.19$ & $0.70 \pm 0.46$ & 36.066 & 0.000 & $2.94 \pm 0.23$ & $0.0 \pm 0.0$ & 86.657 & 0.000 \\
\hline Total & $52.48 \pm 3.71$ & $12.14 \pm 6.03$ & 47.961 & 0.000 & $52.14 \pm 3.23$ & $0.76 \pm 0.87$ & 113.533 & 0.000 \\
\hline
\end{tabular}

*control group; received home remedies; **intervention group; received essential oils; $\mathrm{t}_{0}$ : Paired $\mathrm{t}$ - test; Level of significance at $\mathrm{p} \leq 0.05$ 
Table 7: Post intervention mean scores of children in control and intervention groups in line with Canadian acute respiratory illness and flu scale after 7 days of intervention

\begin{tabular}{|c|c|c|c|c|}
\hline Items & $\begin{array}{l}\text { *Post control group } \\
\bar{x} \pm \mathrm{S} \text {. D }\end{array}$ & $\begin{array}{l}* * \text { Post intervention group } \\
\bar{x} \pm \mathrm{S} \text {. D }\end{array}$ & t. test & P. value \\
\hline Fever & $0.18 \pm 0.38$ & $0.0 \pm 0.0$ & 3.28 & 0.002 \\
\hline Cough & $1.18 \pm 0.48$ & $0.44 \pm 0.50$ & 6.97 & 0.000 \\
\hline Runny nose & $1.20 \pm 0.49$ & $0.30 \pm 0.46$ & 8.654 & 0.000 \\
\hline Vomiting & $0.14 \pm 0.40$ & $0.0 \pm 0.0$ & 2.447 & 0.018 \\
\hline Moody & $0.66 \pm 0.47$ & $0.0 \pm 0.0$ & 3.563 & 0.001 \\
\hline Not interested in what's going on & $0.70 \pm 0.46$ & $0.0 \pm 0.0$ & 10.693 & 0.000 \\
\hline Poor appetite & $0.62 \pm 0.49$ & $0.02 \pm 0.14$ & 7.937 & 0.000 \\
\hline Irritable & $0.58 \pm 0.49$ & $0.0 \pm 0.0$ & 8.226 & 0.000 \\
\hline Not playing well & $0.58 \pm 0.49$ & $0.0 \pm 0.0$ & 8.226 & 0.000 \\
\hline Need extra care & $0.68 \pm 0.47$ & $0.0 \pm 0.0$ & 10.20 & 0.000 \\
\hline Crying more than usual & $0.60 \pm 0.49$ & $0.0 \pm 0.0$ & 8.573 & 0.000 \\
\hline Clinginess of bed & $0.72 \pm 0.45$ & $0.0 \pm 0.0$ & 11.225 & 0.000 \\
\hline Not sleeping well & $0.80 \pm 0.40$ & $0.0 \pm 0.0$ & 14.000 & 0.000 \\
\hline Need medication & $0.86 \pm 0.49$ & $0.0 \pm 0.0$ & 12.27 & 0.000 \\
\hline Sore throat & $0.76 \pm 0.43$ & $0.0 \pm 0.0$ & 12.45 & 0.000 \\
\hline Headache & $0.56 \pm 0.57$ & $0.0 \pm 0.0$ & 6.861 & 0.000 \\
\hline Not responding to parents & $0.62 \pm 0.49$ & $0.0 \pm 0.0$ & 8.941 & 0.000 \\
\hline Can't communicate well & $0.70 \pm 0.46$ & $0.0 \pm 0.0$ & 10.693 & 0.000 \\
\hline Total & $12.14 \pm 6.03$ & $0.76 \pm 0.87$ & 28.62 & 0.000 \\
\hline
\end{tabular}

*control group; received home remedies; **intervention group; received essential oils; $\mathrm{t}$ : Student t-test; Level of significance at $\mathrm{p}$ $\leq 0.05$

Table 8: Correlation Matrix between variables post intervention in the intervention group

\begin{tabular}{llll}
\hline Items & Cough and Sleep & CARFIS & Based assessment \\
\hline Cough and Sleep & & r $0.591^{* * *}$ & r $0.450^{* *}$ \\
CARFIS & P 0.000 & $\mathrm{P} 0.001$ \\
& $\mathrm{r} 0.591^{* *}$ & & $\mathrm{r} 0.761^{* *}$ \\
Based assessment & $\mathrm{P} 0.000$ & $\mathrm{r} 0.450^{* *}$ & $\mathrm{P} 0.000$ \\
& & $\mathrm{P} 0.001$ & $\mathrm{r} 0.761^{* *}$ \\
\end{tabular}

** Correlation is significant at $\mathrm{p} \leq 0.01$ level; $\mathrm{r}$ : Pearson coefficient

\section{Discussion}

Over 25 essential oils are officially used for the treatment of respiratory tract diseases in the European Pharmacopoeia, including: Essential anise oil, bitter fennel fruit, eucalyptus, peppermint, tea tree and thyme. These oils can, according to the Community Herbal Monographs of the Committee on Herbal Medicinal Products (HMPC), be generally used on the basis of long-term use (Pharmacopoea, 2004).

Honey was considered by the World Health Organization to be a potentially valuable demulcent for cough treatment. Honey has a complex chemical composition of carbohydrates, free amino acids, vitamins, trace elements and flavonoids and is a sweet viscous liquid. It also includes compounds that function as antioxidants. It is said to have antibacterial, antiviral and anti-inflammatory effects. Studies of the antimicrobial effect of honey have demonstrated its broad-spectrum antimicrobial actions against various gram-positive and gram-negative bacteria. It is also active in the upper respiratory tract against common bacteria, including Staphylococcus aureus and Streptococcus faecalis, among others. Due to restricted immunity to Clostridium Botulinum, a potential contaminant, the use of honey is prohibited under the age of one (Ali et al., 2015). Similarly to this evidence, (Ahmadi et al., 2013) reported that honey reduced the severity and frequency of day and night coughs versus diphenhydramine $(\mathrm{p}<0.02)$.

Over the last few decades, Complementary and Alternative Medicine (CAM) has become more popular worldwide, as CAM approaches are considered safe, efficient, accessible and affordable. Approximately $12 \%$ of children and $40 \%$ of adults in the United States use CAM, according to a survey carried out by the Centers for Disease Control and 
Prevention, displaying higher rates among children with respiratory complaints (Philp et al., 2012).

As few clinical trials have reported the benefits of herbal mixtures, the current study was conducted to evaluate the effect of essential oils versus home remedies on relieving signs and symptoms of acute respiratory tract infection among children. Sustaining and growing education for women will play a crucial role in dynamic continued improvement in health outcomes. It increases their self-reliance, ability to make health decisions and to seek better health care. Slightly less than one third of mothers in the two groups at the present study had university educational level. This helped for women cooperation, accepting and following up their children (Kamali et al., 2018).

The current research examined the distribution of respondents by age and observed that the largest proportion of children ranged from >3-6 years of age, considering the fact that small children of pre-school age are susceptible to this form of infection. In addition, there were marginally more girls than boys. These results are inconsistent with a study done in Saudi Arabia by (Shuhayb et al., 2018) who stated that children from 1-3 years constituted a large portion in that study and boys were more than girls, theses discrepancies may be due to the difference between the study nature and design used, in addition to the variation of demographic characteristics between Egypt and Saudi Arabia.

Coughing is one of the most common reasons for routine pediatric practice consultation and becomes very worrying when it persists for a long period of time; it negatively affects daily activities and also has an adverse effect on the quality of life of the child and the parents or caregivers (Chang, 2010). Cough, more than other symptoms, is disruptive, preventing the sick child and the family from sleeping and might result in frustration. In the absence of effective antiviral treatment for URI, parents try to find products that may relieve cough until the illness resolves (Paul et al., 2007).

Similarly, the current study found that most children had an average of 2-3 ARI episodes per year, but that number increased to 5 for some children. These findings are in line with a study done by (Javid et al., 2019) who stated that $65 \%$ of children at least have 1-3 episode of URTI per year, followed by 24\% who have 4-6 episodes per year.

Most of the children use one or more products in a given week. Over-The-Counter (OTC) products, mostly cough and cold medications, account for most medication exposures. Cough and cold preparations usually comprise several medications, including antitussives, expectorants, antihistamines, decongestants and antipyretics such as acetaminophen (Ujunwa and Ezeonu, 2014). The current study coincides with these in which the treatment given was $76 \%$ antipyretics, $38 \%$ antibiotics, $34 \%$ decongestant and $26 \%$ cough suppressants among intervention group. (Alrafiaah et al., 2017); mentioned that some participants would use antibiotics based on pharmacists' recommendations. Similarly, (Ocan et al., 2014) had similar outcomes for the use of antibiotics in treating acute URTIs in children accounting for $44.8 \%$.

A scratchy throat may be settled down by several warm remedies such as teas, though herbs such as peppermint or eucalyptus can be more helpful. Evidencebased complementary and alternative medicine studies have found that treatments, including peppermint and anise, have a soothing effect on the throat of people with upper respiratory tract infections. These remedies may help break up mucus and ease the pain and inflammation caused by pneumonia (Hewlings and Kalman, 2017; Wani and Kumar, 2018).

The home remedies were found as a treatment with no side effects and low cost that can be used to ameliorate symptoms triggered by viral respiratory tract infections. The current study demonstrated that, there was a marked decrease in symptoms assessed by mothers of the control group who drank varieties of warm home remedies as fatigue, sore throat and difficulty in breathing post intervention with highly statistically significant difference at $(\mathrm{P}<0.01)$ between pre and post intervention. Furthermore, there was a marked decrease in total sings assessed by physician of control group as stridor and dyspnea post intervention with highly statistically significant difference at $(\mathrm{P}<0.01)$ These results coincide with a study done by (Brinckmann et al., 2003) who reported that one option for treating sore throat and other URTI symptoms was a herbal tea preparation that may act both locally and systemically and demonstrated notable relief of pain in patients with acute pharyngitis within 5 min after drinking a traditional demulcent herbal tea, compared with placebo.

It is evident that cough is a common symptom in pediatric practice and can be particularly troubling to children and their parents, leading to discomfort, sleeplessness, missed school days and workdays. A study done in USA 2012 proved that cough disturbed sleep in $88 \%$ of children and $72 \%$ of parents (De Blasio et al., 2012). The present study displayed that, there was a marked decreased in total cough and sleep difficulty on the previous night before diseases among intervention group as reduced effect of children's 
cough on their ability to sleep post intervention with highly statistically significant difference at $(\mathrm{P}<0.01)$ between pre and post intervention. Additionally, the entire intervention group had mild level of total cough and sleep difficulty after 7 days post intervention. While, less than three quarters $(72 \%)$ of the control group had moderate level of total cough and sleep difficulty after 7 days post intervention. Clinical study done by (Cukic et al., 2011) indicated that appropriate asthma control can result in better sleep quality in asthmatic patients. Similarly, in the current study, treatment of patients with herbal mixture improved sleep quality as well as other symptoms.

In the randomized double-blind trial done in Israel by (Ben-Arye et al., 2011) to study the effect of a herbal preparation on URTI symptoms compared to placebo, patients reported a significant decrease in URTI symptoms $20 \mathrm{~min}$ post administration. Likewise, in another double-blind randomized controlled herbal trial done by (Dirjomuljono et al., 2008) who examined the effect of two herbs, Nigella sativa and Phyllanthus niruri, on patients with acute tonsillo-pharyngitis symptoms, they found that the alleviation of swallowing pain and difficulty was noticed only after 5-6 h, perhaps due to a systemic effect (oral tablets versus spray application in other studies). Other promising remedies are the traditional Japanese (Kampo medicine) formulas named Hochuekkito (TJ-41) and Juzentaihoto (TJ-48) that activate the mucosal immune system of upper respiratory tract (Kiyohara et al., 2006).

As well, (Chang et al., 2006) investigated the Chinese herbal medicine formula, STA-1 (consisting of 9 herbs which are: Root of Rehmannia glutinosa, root bark of Paeonia suffruticosa, fruit of Cornus officinalis, rhizome of Alisma orientalis, root of Dioscorea opposita, root of Ophiopogon japonicus, root of Glycyrrhiza uralensis, root of Panax quinquefolius and tuber of Pinellia ternate) for treatment of allergic asthma and demonstrated a statistically significant reduction in symptoms' scores.

In correspondence to these results, the existing study publicized that there was a marked decreased in all items of the Canadian acute respiratory illness and flu scale of the intervention group as decreased fever, vomiting, irritability, sore throat and headache post intervention with highly statistically significant difference at $(\mathrm{P}<0.01)$ between pre and post intervention. As well, there was a highly statistically significant difference in all items of the Canadian acute respiratory illness and flu scale between control and intervention groups after 7 days post intervention.
The current study designed an application of safe and effective alternative approach of essential oils in a spray form; it intended to gain the local benefits of these evaporating oils, which may achieve better penetration of the tonsils' folders and other pharyngeal structures. The rapid symptom improvement following application of the spray may be explained by an antiinflammatory and analgesic effect. Indeed, this study cannot conclusively determine that the combination of the 5 herbs is indeed essential. Additionally, the advantages of the oils preparation reported in the present study may not only be limited to children's relief due to symptoms improvement, but also may be used to decrease antibiotic resistance as plants extracts are potential sources of antimicrobial and resistancemodifying agents (Cruz et al., 2014). Moreover, utilization of Complementary and Alternative Medicine (CAM) therapies, including herbal preparations, could reduce prescribing antibiotics in cases when there is no clinical indication, such as viral infections (Alumran et al., 2011).

\section{Conclusion and Recommendations}

Based on the existing study findings, it can be concluded that:

- Children who received essential oils displayed faster recovery of acute respiratory tract infection than those who received home remedies

- The essential-oils extracts of five plants proved to be effective in alleviating signs of acute respiratory tract infection

- Further randomized clinical trials using different mixtures of herbs should be conducted on a larger group of patients to evaluate the most effective herbal mixture, dose and duration of treatment

\section{Acknowledgement}

The authors would like to offer their sincere thanks to all mothers and children who participated in this study. Also, the study would not have been possible without the co-operation of the staff of the National Medical Institute of Damanhour City.

\section{Funding Information}

The authors received no financial support for the research, authorship and/or publication of this article.

\section{Author Contributions}

\section{Abeer Abd El-Aziz Mohamed Madian:}

- Organized the study 
- $\quad$ Supervised the study

- Provided critical review of the article

- Approved the final article

\section{Mohammad Mahmoud Abd-Alhaseeb:}

- Study concept and design

- $\quad$ Prepared the herbal therapy and provide doses and therapeutic regimen

- Provided critical review of the article

- Approved the final article

\section{Ebtsam Salah Yonis Mahrous:}

- Study concept and design

- Collect data

- Performed the analysis and drafted the article

- Approved the final article

\section{Rodaina Ahmed Mokbel:}

- Study concept and design

- Collect data

- Performed the analysis and drafted the article

- Approved the final article

\section{Ethics}

This article is original and contains unpublished material. The corresponding author confirms that all of the other authors have read and approved the manuscript and no ethical issues involved.

\section{References}

Ahmadi, M., Moosavi, S. M., \& Zakeri, S. (2013). Comparison of the effect of honey and diphenhydramine on cough alleviation in 2-5-yearold children with viral upper respiratory tract infection. Journal of Gorgan University of Medical Sciences, 15(2).

Ali, B., Al-Wabel, N. A., Shams, S., Ahamad, A., Khan, S. A., \& Anwar, F. (2015). Essential oils used in aromatherapy: A systemic review. Asian Pacific Journal of Tropical Biomedicine, 5(8), 601-611.

Alrafiaah, A. S., Alqarny, M. H., Alkubedan, H. Y., AlQueflie, S., \& Omair, A. (2017). Are the Saudi parents aware of antibiotic role in upper respiratory tract infections in children?. Journal of Infection and Public Health, 10(5), 579-585.

Alumran, A., Hurst, C., \& Hou, X. Y. (2011). Antibiotics overuse in children with upper respiratory tract infections in Saudi Arabia: risk factors and potential interventions. Clinical Medicine and Diagnostics, 1(1), 8-16.
Bardia, A., Nisly, N. L., Zimmerman, M. B., Gryzlak, B. M., \& Wallace, R. B. (2007, May). Use of herbs among adults based on evidence-based indications: findings from the National Health Interview Survey. In Mayo Clinic Proceedings (Vol. 82, No. 5, pp. 561-566). Elsevier.

Ben-Arye, E., Dudai, N., Eini, A., Torem, M., Schiff, E., \& Rakover, Y. (2011). Treatment of upper respiratory tract infections in primary care: a randomized study using aromatic herbs. Evidence-based Complementary and Alternative Medicine, 2011.

Breuner, C. C. (2002). Complementary medicine in pediatrics: a review of acupuncture, homeopathy, massage and chiropractic therapies. Current Problems in Pediatric and Adolescent Health Care, 32(10), 353-384.

Brinckmann, J., Sigwart, H., \& van Houten Taylor, L. (2003). Safety and efficacy of a traditional herbal medicine (Throat Coat $\AA$ ) in symptomatic temporary relief of pain in patients with acute pharyngitis: A multicenter, prospective, randomized, double-blinded, placebo-controlled study. The Journal of Alternative \& Complementary Medicine, 9(2), 285-298.

Brini, I., Guerrero, A., Hannachi, N., Bouguila, J., OrthHöller, D., Bouhlel, A., ... \& Stoiber, H. (2017). Epidemiology and clinical profile of pathogens responsible for the hospitalization of children in Sousse area, Tunisia. Plos one, 12(11), e0188325.

Carr, R. R., \& Nahata, M. C. (2006). Complementary and alternative medicine for upper-respiratory-tract infection in children. American Journal of HealthSystem Pharmacy, 63(1), 33-39.

Chang, A. B. (2010). Pediatric cough: children are not miniature adults. Lung, 188(1), 33-40.

Chang, T. T., Huang, C. C., \& Hsu, C. H. (2006). Clinical evaluation of the Chinese herbal medicine formula STA-1 in the treatment of allergic asthma. Phytotherapy Research: An International Journal Devoted to Pharmacological and Toxicological Evaluation of Natural Product Derivatives, 20(5), 342-347.

Chien, C., Marriott, J. L., Ashby, K., \& Ozanne-Smith, J. (2003). Unintentional ingestion of over the counter medications in children less than 5 years old. Journal of Paediatrics and Child Health, 39(4), 264-269.

Cohen, H. A., Varsano, I., Kahan, E., Sarrell, E. M., \& Uziel, Y. (2004). Effectiveness of an herbal preparation containing echinacea, propolis and vitamin $\mathrm{C}$ in preventing respiratory tract infections in children: a randomized, double-blind, placebocontrolled, multicenter study. Archives of Pediatrics \& Adolescent Medicine, 158(3), 217-221. 
Cruz, M. J., Dourado, L. F., Bodevan, E. C., Andrade, R. A., \& Santos, D. F. (2014). Medication use among children 0-14 years old: population baseline study. Jornal de Pediatria, 90(6), 608-615.

Cukic, V., Lovre, V., \& Dragisic, D. (2011). Sleep disorders in patients with bronchial asthma. Materia Socio-Medica, 23(4), 235.

De Blasio, F., Dicpinigaitis, P. V., Rubin, B. K., De Danieli, G., Lanata, L., \& Zanasi, A. (2012). An observational study on cough in children: epidemiology, impact on quality of sleep and treatment outcome. Cough, 8(1), 1-6.

Dirjomuljono, M., Kristyono, I., Tjandrawinata, R. R., \& Nofiarny, D. (2008). Symptomatic treatment of acute tonsillo-pharyngitis patients with a combination of Nigella sativa and Phyllanthus niruri extract. International Journal of Clinical Pharmacology and Therapeutics, 46(6), 295.

Francis, A., Cho, Y., \& Johnson, D. W. (2015). Honey in the prevention and treatment of infection in the CKD population: a narrative review. Evidence-Based Complementary and Alternative Medicine, 2015.

Hewlings, S. J., \& Kalman, D. S. (2017). Curcumin: a review of its effects on human health. Foods, 6(10), 92.

Jacobs, B., Young, N. L., Dick, P. T., Ipp, M. M., Dutkowski, R., Davies, H. D., ... \& Wang, E. E. (2000). Canadian Acute Respiratory Illness and Flu Scale (CARIFS): development of a valid measure for childhood respiratory infections. Journal of Clinical Epidemiology, 53(8), 793-799.

Javid, A., Haghi, N. M., Emami, S. A., Ansari, A., Zojaji, S. A., Khoshkhui, M., \& Ahanchian, H. (2019). Short-course administration of a traditional herbal mixture ameliorates asthma symptoms of the common cold in children. Avicenna Journal of Phytomedicine, 9(2), 126.

Kamali, Z., Abedian, Z., SaberMohammad, A., \& Dehnavi, Z. M. (2018). The effect of small group teaching on quality of life in pregnant women with nausea and vomiting: A clinical trial. Journal of Education and Health Promotion, 7.

Kiyohara, H., Nagai, T., Munakata, K., Nonaka, K., Hanawa, T., Kim, J., \& Yamada, H. (2006). Stimulating effect of Japanese herbal (kampo) medicine, hochuekkito on upper respiratory mucosal immune system. Evidence-Based Complementary and Alternative Medicine, 3(4), 459-467.

Köteles, F., Babulka, P., Szemerszky, R., Dömötör, Z., \& Boros, S. (2018). Inhaled peppermint, rosemary and eucalyptus essential oils do not change spirometry in healthy individuals. Physiology \& Behavior, 194, 319-323.
Liu, L., Oza, S., Hogan, D., Chu, Y., Perin, J., Zhu, J., ... \& Black, R. E. (2016). Global, regional and national causes of under-5 mortality in 2000-15: an updated systematic analysis with implications for the Sustainable Development Goals. The Lancet, 388(10063), 3027-3035.

McKay, D. L., \& Blumberg, J. B. (2006). A review of the bioactivity and potential health benefits of peppermint tea (Mentha piperita L.). Phytotherapy Research: An International Journal Devoted to Pharmacological and Toxicological Evaluation of Natural Product Derivatives, 20(8), 619-633.

Ocan, M., Bwanga, F., Bbosa, G. S., Bagenda, D., Waako, P., Ogwal-Okeng, J., \& Obua, C. (2014). Patterns and predictors of self-medication in northern Uganda. PloS One, 9(3), e92323.

Ouedraogo, A. S., Pierre, H. J., Bañuls, A. L., Ouédraogo, R., \& Godreuil, S. (2017). Emergence and spread of antibiotic resistance in West Africa: contributing factors and threat assessment. Medecine et Sante Tropicales, 27(2), 147-154.

Paul, I. M., Beiler, J., McMonagle, A., Shaffer, M. L., Duda, L., \& Berlin, C. M. (2007). Effect of honey, dextromethorphan and no treatment on nocturnal cough and sleep quality for coughing children and their parents. Archives of Pediatrics \& Adolescent Medicine, 161(12), 1140-1146.

Pharmacopoea, E. (2004). Directorate for the Quality of Medicines and healthcare of the Council of Europe. Strasburg, France.

Philp, J. C., Maselli, J., Pachter, L. M., \& Cabana, M. D. (2012). Complementary and alternative medicine use and adherence with pediatric asthma treatment. Pediatrics, 129(5), e1148-e1154.

Rowlinson, E., Dueger, E., Mansour, A., Azzazy, N., Mansour, H., Peters, L., ... \& Kandeel, A. (2017). Incidence and etiology of hospitalized acute respiratory infections in the Egyptian Delta. Influenza and Other Respiratory Viruses, 11(1), 23-32.

Shuhayb, Z. A., Haddad, S. A., Yahya, K. A., \& Khawaja, R. (2018). Parents' Management of Acute Upper Respiratory Tract Infections in Children, Al Ahsa, Saudi Arabia. International Journal of Scientific Study 6, 99-104. https://www.ijsssn.com/uploads/2/0/1/5/20153321/ijss_aug_oa18__2018.pdf

Troeger, C., Forouzanfar, M., Rao, P. C., Khalil, I., Brown, A., Swartz, S., ... \& Mokdad, A. H. (2017). Estimates of the global, regional and national morbidity, mortality and aetiologies of lower respiratory tract infections in 195 countries: a systematic analysis for the Global Burden of Disease Study 2015. The Lancet Infectious Diseases, 17(11), 1133-1161. 
Abeer Abd El-Aziz Mohamed Madian et al. / American Journal of Infectious Diseases 2021, 17 (1): 7.21

DOI: 10.3844/ajidsp.2021.7.21

Ujunwa, F. A., \& Ezeonu, C. T. (2014). Risk factors for acute respiratory tract infections in under-five children in enugu Southeast Nigeria. Annals of Medical and Health Sciences Research, 4(1), 95-99.
Wani, S. A., \& Kumar, P. (2018). Fenugreek: A review on its nutraceutical properties and utilization in various food products. Journal of the Saudi Society of Agricultural Sciences, 17(2), 97-106. 